\title{
O COMPROMISSO INSTITUCIONAL DA UNIVERSIDADE COM A FORMAÇÃO DE PROFESSORES
}

\author{
Sílvia Ester Orrú \\ Coordenadora e professora do curso de Pedagogia da UNIFEOB, Brasil.
}

\section{INTRODUÇÃO}

O presente texto vem discutir a questão da didática, ou melhor, da aula no ensino superior num contexto em que a mesma se apresenta como parte importante do processo de mudança de paradigma onde se encontram as universidades tendo em vista o seu compromisso institucional com a formação de professores.

A universidade surgiu na Europa no período gótico em meados dos séculos XI e XII. Até então, os estudos superiores aconteciam em mosteiros ou nas escolas catedralícias, onde eram formados os pensadores da Igreja Católica e seus administradores. Na verdade, a primeira universidade constituída fora a de Bologna, na Itália, fundado no ano de 1088, especializada na área de direito. Conforme Castanho, S.E.M.:

A mais famosa de todas as instituições medievais de educação superior foi a Universidade de Paris, estabelecida na Segunda metade do século XII, entre 1150 e 1170. Até a passagem do século XV para o XVI, formou-se na Europa cerca de 80 universidades. Entre as mais célebres cumpre destacar as de Pádua em 1222; Nápoles, 1224; Salamanca, 1230; Siena, 1242; Oxford, 1249; Cambridge, 1284; Coimbra, 1308; Pisa, 1343; Praga, 1348; Cracóvia, 1364; Viena, 1365; Heidelberg, 1385; Colônia, 1388; Leipzig, 1409; Louvain, 1425; Tübingen, 1477; Barcelona, 1477; Copenhague, 1479; Valência, 1501 e Sevilha, 1505 (op. cit.; p. 17).

Em meio à intensa mobilidade típica da Idade Média e do significativo crescimento intelectual como resultado do confronto entre a cristandade e a ciência experimental, a universidade em toda sua trajetória histórica tem tido suas lutas e desafios para superar a crise de cristalismo institucional vivenciada no passar dos anos. Ela caminhou por modelos clássicos que a caracterizavam como instituição, tais como: o imperial napoleônico, o idealista alemão, o elitista inglês e o utilitarista norte-americano até deparar-se com os paradigmas contemporâneos conhecidos como o democrático-nacional-participativo e o neoliberalglobalista-plurimodal, (CASTANHO, S.E.M. 2000: 32, 35) conhecendo em 1998 pela Unesco, a Declaração mundial sobre a educação superior no século XXI: Visão e ação, assumindo um compromisso com ambos os modelos contemporâneos e aproximando-se do referencial crítico-cultural-popular onde se encontram os manifestos contra a exclusão e o clamor pela liberdade.

Contudo, a universidade tem sido o local, a instituição, o abrigo, o celeiro onde o saber é semeado, plantado, cuidado e expandido. É por meio dela que o saber pode transcender às paredes invisíveis construídas para "segurar" o povo de sua alforria da alienação para a construção de seu saber, do saber fazer e do saber ser. Mas para tanto, é preciso haver uma articulação em torno das questões que envolvem a universidade e a sociedade na qual está inserida, sugerindo que posições de neutralidade não a impeçam de cumprir a sua missão: a de construir e disseminar conhecimentos e de educar para a vida, unindo a sabedoria da reflexão e audácia da ação sobre a reflexão. 
Seguem, portanto, alguns aspectos necessários para serem refletidos e discutidos, a fim de que a universidade enquanto instituição compromissada com a educação cumpra sua missão, sendo o professor, o indispensável articulador e mediador entre o saber e aquele que o deseja saber construir: 0 aluno.

\section{O EXERCÍCIO CRÍTICO}

O século XIX foi marcado pelo incessante questionamento acerca das preocupações existentes sobre o que aparentava ser consciência do real mascarada por uma consciência falseada por processos histórico-sociais influenciados pela manipulação das relações sociais dominadas por classes ou setores.

Nesta época, Marx e Engels trouxeram significativa contribuição à filosofia moderna e à sociologia do conhecimento. Era o conceito de ideologia.

O conceito de ideologia é um dos mais ricos instrumentos elaborados pelo pensamento humano para a explicação de seus próprios processos de expressão (...) A teoria marxista da ideologia assume, assim, um lugar referencial, tanto do ponto de vista histórico quanto do ponto de vista epistemológico, na longa história da formação e do desenvolvimento do conceito (SEVERINO, 1986: 3).

Assim, o presente século fora notado como uma época marcada pela prática da desconfiança e do desenvolvimento do senso crítico a fim de que as "massas humanas" se apercebessem que ideologias fundamentadas em ilusões eram construídas para favorecer o domínio e os interesses de uma determinada classe ou setor social.

Já nos século XX, as décadas de 60 e 70, clamaram pela "criticidade" ante situações político-sociais com o propósito de exercitar o senso crítico no contexto global do viver. Tal prática pode ser vista a partir de situações, falas e publicações de intelectuais, líderes políticos, sindicais e religiosos que faziam da criticidade sua arma poderosa em meio à sociedade e seus conflitos. E assim, acordavam as camadas sociais para o brado crítico.

Ocorre que, embora fosse necessário tal despertar, muitos se deixaram levar pelo furor da criticidade de modo a atolarem-se numa prática ingênua da mesma. De acordo com Morais:

Acontece que, ao grande apelo por criticidade, respondeu-se às vezes com um não saber direito quais as possibilidades e quais os limites do senso crítico, bem como com certa ausência de autocrítica que predispunha à arrogância de se imaginar que se pode criticar tudo, todo o tempo, com ou sem o devido conhecimento daquilo que se fosse criticar. A essa extralimitação arrogante corresponde a idéia ingênua de que Ter senso crítico consiste em atirar-se necessariamente contra toda situação configurada, pronunciamento feito ou texto com o qual se tome contato; tudo isso na incapacidade de avaliar e reconhecer os próprios limites e, em conseqüência, tratar criticamente aquilo que não se entende (2000:54).

Percebe-se, portanto, que a autêntica criticidade ou o espírito crítico, não estão ligados a fanatismos doutrinários ou dogmatismos. Pelo contrário, o espírito crítico é inevitável para os avanços do pensamento da humanidade. Ele não é ingênuo, contraditório ou hostil a toda idéia e iniciativa, mas equilibrado moral e intelectualmente, sensato e criterioso. Ele auxilia na preservação e no respeito da individualidade dos outros e da minha própria, aceitando as particularidades e as diferenças existentes em cada um. Assim sendo, o exercício crítico está ligado a uma atitude de humildade do ser humano. Deveras, entendamos o sentido de humildade:

A humildade não é a depreciação de si, ou é uma depreciação sem falsa apreciação. Não é ignorância do que somos, mas, ao contrário, conhecimento, ou reconhecimento, de tudo o que não somos (...) A humildade é virtude lúcida, sempre insatisfeita consigo mesma, mas que o seria ainda mais se não o fosse. É a virtude do homem que sabe não ser Deus (Comte-Sponville, 1995:153). 
A sala de aula é, sem dúvida, o espaço onde o senso crítico deve ser gerado e alimentado, principalmente, porque é nesse local que se dá àformação intelectual e devida para não apena s o trabalho profissional, mas também para a cidadania, onde o crescimento individual, político e social é indispensável. Para tanto, a sala de aula não deve ser "fechada" e austera frente à realidade a qual pertencem seus alunos.

O professor, mediador indispensável no processo ensino-aprendizagem, precisa estar consciente de seu papel na formação de seu aluno. Tal consciência não é suficiente se somente se prender aos aspectos formais desse processo. É preciso atentar para detalhes que podem de fato fazer a diferença para a elevação do espírito crítico, pois a prática do educador observada por seu aluno é o espelho para sua formação.

Portanto, o exercício critico vai além de meras palavras e afirmações sustentadas em "achômetros". Ele se mostra presente quando o professor se põe a discutir os critérios de avaliação junto com seus alunos, o conteúdo programático a ser estudado. Quando chama seu aluno a debater e expor suas idéias por meio de fala oral ou escrita, mesmo que estas sejam contrárias as suas próprias. Ele se faz presente na leitura, interpretação e discussão de textos. Atenta para leituras e re-leituras significativas, para mensagens submersas em entrelinhas, mas também no ouvir o outro. Enfim, o espírito crítico excede a crítica.

\section{A CRIATIVID ADE}

O momento atual revela evidências da necessidade de transformações ocorrerem nos âmbitos sociais, políticos e educacionais. É o homem desejando mais do que aquilo que é considerado como básico e suficiente para se viver, conforme se pode perceber na letra composta pelos Titãs como protesto à indiferença do sistema brasileiro de governo æ̀̀ necessidades do povo

Bebida é água. Comida é pasto. Você tem sede de que? Você tem fome de que? A gente não quer só comida. A gente quer comida, diversão e arte. A gente não quer só comida. A gente quer saída para qualquer parte. A gente não quer só comida. A gente quer bebida, diversão, balé. A gente não quer só comida. A gente quer a vida como a vida quer. Bebida é água. Comida é pasto. Você tem sede de que? Você tem fome de que? A gente não quer só comer. A gente quer comer, quer fazer amor. A gente não quer só comer. A gente quer prazer pra aliviar a dor. A gente não quer só dinheiro. A gente quer dinheiro e felicidade. A gente não quer só dinheiro. A gente quer inteiro e não pela metade (1997).

Entretanto, essas exigências não se limitam somente a necessidade de uma cultura e ação social amplas que permeiem toda a sociedade. Elas estão ligadas também as questões de cunho educacional que incentivem e preparem nossos alunos, desde a educação básica ao ensino superior, para buscarem alternativas solutivas para a construção do novo.

Mas, o que dizer de nossas universidades? São belas na magnitude de seus campi. Possuem bibliotecas de boa qualidade. Professores titulados. Laboratórios de informática para a intimidade com as novas tecnologias e comunicação mundial. Têm laboratórios modernos das mais distintas áreas de atuação técnica e pedagógica. Atendimento personalizado. E ... inúmeros outros atributos quantitativos e qualitativos que Ihes atribuem conceitos positivos ou não para continuarem exercendo suas atividades acadêmicas. Porém, "a gente quer inteiro e não pela metade". Há algo que pode ser visto como sendo a alma da universidade e que dá razão à existência de todos os recursos mencionados ou não, possuídos por uma universidade. Ao nosso ver, essa alma se chama prática pedagógica. 
Quando se fala em prática pedagógica, não se está limitando a mesma apenas aqueles que a conhecem por terem se graduado em Pedagogia. A prática pedagógica está implícita em todas as áreas onde a produção do conhecimento e o princípio metodológico se unem como partes integrantes do processo ensino-aprendizagem do qual o professor é o interlocutor, o mediador.

Estudos realizados acerca da prática pedagógica evidenciam que vários princípios metodológicos adotados por professores e percebidos pelos alunos interferem no favorecimento do processo de aprendizagem dos mesmos. Dentre as qualidades descritas pelos alunos do bom professor, estão:

- o professor é didático,

- suas aulas são interdisciplinares,

- integra ensino com pesquisa,

- transmite o saber científico de maneira compreensiva,

- gosta do que faz,

- tem conhecimento de sua área de ensino,

- estimula o espírito crítico,

- sabe contextualizar o assunto que está ensinando,

- trabalha a realidade do aluno como ponto de partida para a construção do conhecimento,

- é criativo.

Analisando os itens acima citados, pode-se perceber que praticamente todos são inerentes a um item: o professor é criativo. O professor criativo consegue que sua prática pedagógica alcance a realidade e a necessidade que seu aluno apresenta. Portanto, ele relaciona de fato a teoria com a prática. Nesta relação teoria e prática está presente à idéia de que ensinar é muito mais do que trans mitir e reproduzir conhecimentos. Deveras, a criatividade também é um princípio metodológico e uma necessidade a ser trabalhada pela universidade.

Como já fora dito, o momento atual reclama profundas transformações e rupturas nos diversos níveis da atividade humana. Logo, a educação também precisa, urgentemente, de uma nova postura e esta apenas se dará por meio da atuação transformadora do professor dentro da sala de aula. Nisto se implica a tarefa de preparar seus alunos para o exercício da autonomia intelectual e da cidadania por meio da busca de inovações significativas no ensinar a pensar e aprender, numa contínua transposição paradigmática do que se entende por aula universitária.

Pensando a criatividade como princípio metodológico para uma prática pedagógica significativa no processo ensino-aprendizagem, há necessidade de se conhecer quais seriam os fatores relevantes que poderiam ser objetos de atenção do professor. Castanho, M.E.L.M. (2000:83) descreve oito critérios da criatividade apresentados pr Guilford ${ }^{1}$ e Lowenfeld ${ }^{2}$ em trabalhos realizados em campos diferentes e isolados, e que se coincidem sobre os processos da mesma.

\footnotetext{
${ }_{1}^{1}$ Psicólogo da Universidade da Califórnia. Trabalhou os critérios da criatividade na área da ciência.

${ }^{2}$ Psicólogo da Universidade da Pensilvânia. Trabalhou os critérios da criatividade na área da arte.
} 
São os seguintes os oito critérios da criatividade por eles apresentados: 1) sensibilidade aos problemas (o que permite notar as sutilezas, o pouco comum, as necessidades e os defeitos nas coisas e nas pessoas); 2) estado de receptividade (manifestando que o pensamento está aberto e é fluente); 3) mobilidade (capacidade de adaptar-se rapidamente a novas situações); 4) originalidade (propriedade considerada suspeita pela ordem social e uma das mais importantes do pensamento divergente); 5) atitude para transformar e redeterminar (atitude de transformar, estabelecer novas determinações dos materiais diante de novos empregos); 6) análise (ou faculdade de abstração por meio da qual passamos da percepção sincrética das coisas à determinação dos detalhes. Permite reconhecer as menores diferenças para descobrir a originalidade e a individualidade); 7) síntese (consiste em reunir vários objetos ou partes de objetos para dar-Ihes um novo significado); 8)organização coerente (é por meio dessa atitude que o homem harmoniza seus pensamentos, sua sensibilidade, sua capacidade de percepção com sua personalidade).

Nestes termos, pode-se salientar que o professor que deseja transformar sua prática pedagógica encontra-se numa situação de mudança de paradigma e que ele, enquanto ser histórico em um contexto sócio-político, deve enxergar-se como participante da descoberta e da possibilidade de construção de uma história que altere o rumo da humanidade. Para tanto, o professor deve entender que o espaço da sala de aula também abriga a dúvida, a inquietação, àarte, o trabalho com textos, o silêncio, o debate, a poesia, os filmes, o individual e o coletivo, a inovação e o princípio, os valores, a ação e a reflexão, o cotidiano, o sonho, o conteúdo e a vivência, os recursos materiais e tecnológicos, a interdisciplinaridade e transdisciplinaridade, enfim, o gosto pelo ensino e pelo aprender junto com o aluno.

Finalmente, a prática pedagógica envolvida pelo processo da criatividade articula a função de ensinar com o compromisso com a educação; a necessidade de aprender com o gosto pelo aprender. A criatividade coloca em situação comum o professor e seu aluno, motivando-os a exercerem sua função e seu papel na transformação e na construção de sua própria história.

\section{INTENCIONALIDADE}

A intencionalidade é um componente central da prática pedagógica, clareando o caminho e o sentido do processo ensino-aprendizagem. Ela é indispensável ao professor que almeja a compreensão e o entendimento daquilo que ensina pelos seus alunos. Ela não ocorre devido o grande conhecimento que o professor tem de sua área de atuação, nem tão pouco pelo uso de eficientes recursos tecnológicos. A intencionalidade na prática pedagógica se dá no momento em que o professor, aqui chamado como mediador, decide orientar a interação com seu aluno, chamado como mediado, para um determinado alvo e com objetivos estabelecidos; selecionando, adaptando e interpretando o estímulo específico, no qual ele trabalha ativamente, salientando total atenção para o mesmo, ocorre a mediação intencional que, sendo recebida pelo mediado, será intrinsecamente adequada às suas necessidades, envolvendo deste modo, tanto um como outro, em uma interação intencional.

Com o isolamento intencional do estímulo a ser interagido com o mediado e a interpretação realizada pelo mediador, serão alcançadas, através desse processo relacional, respostas advindas daquele que sofre a mediação. A tais respostas, dá-se o nome de reciprocidade como sendo uma indicação de sua ação receptiva e de seu envolvimento no processo de aprendizagem, estando aberto para os inputs propostos pelo mediador, apresentando-se como um ser participativo desse processo.

É crucial a existência da reciprocidade na interação e a intencionalidade do mediador para a estruturação das circunstâncias pelas quais o mediado atravessará. 
A reciprocidade e a intencionalidade ocorrerão desde 0 instante em que o professor-mediador decidir estar organizando os estímulos, provendo o ambiente de aprendizagem, aprontando previamente 0 material, instigando e provocando a curiosidade e a motivação sobre os conteúdos, considerando a necessidade de destinar tempo para verificar o valor das atividades efetuadas pelo mediado, demonstrando satisfação diante de suas conquistas e incentivo e ânimo em suas re-explicações quando o mesmo ainda não superou suas dificuldades, sendo dedicado e paciente com alunos mais passivos, revendo e reinventando formas de re-explicações para a ocorrência de aprendizagem, valorizando sua produção e explorando a situação de aprendizagem por meio de questões que venham proporcionar interações dinâmicas para ultrapassar as barreiras e superar as dificuldades contidas em determinadas atividades.

A esta intensificação do estímulo que provoca uma resposta no mediado para o mediador, evidenciando reciprocidade, Feuerstein ${ }^{3}$ dá o nome de "estado de vigilância". Portanto, não é somente a intenção de intervir e interpretar que instigará a ocorrência desse "estado de vigilância", mas sim, a procura dinâmica da atenção do mediado para o estímulo e sua mediação intencionalmente proposta.

É comum haver situações em que o educador se sente impedido de provocar a existência de intencionalidade e reciprocidade na sala de aula. Algumas vezes isso pode ocorrer devido à espera do educador pela manifestação interacional do aluno, crendo ser mais importante que este inicie tal interação. Infelizmente, nesse caso, não haverá intencionalidade.

Pensando em uma situação invertida, o educador poderá iniciar de maneira ativa sua interação com alunos por meio de uma aula bem preparada e motivada. Contudo, os alunos podem mostrar-se cansados ou desinteressados pelo conteúdo por qualquer motivo, neste caso, não haverá a reciprocidade.

Tanto a intencionalidade como a reciprocidade acontecem de modo natural no desenvolvimento do ser humano desde criança. Porém, com o tempo, ambas poderão tornar-se menos natural diante de determinadas situações, como acontece dentro da sala de aula.

Para tanto, é preciso ter ciência de que há três elementos que estão amplamente envolvidos nesse processo: o mediador que pode variar sua atuação intencional por meio da linguagem utilizada, do ritmo como recursos realçadores da intencionalidade; o mediado que a partir da centralização de sua atenção, sua condição de interesse e predisposição para aceitar as solicitações que the são feitas efetuará a reciprocidade e o estímulo que variará de acordo com a amplitude de intencionalidade e reciprocidade por meio da apresentação de idéias e de materiais.

\section{AVALIAÇÃO}

A avaliação compreende uma etapa do processo de ensino-aprendizagem, estando relacionada com as competências e as habilidades a serem desenvolvidas na formação do futuro profissional. Tem característica diagnóstica, formativa e somativa. Constitui-se de um processo dinâmico, participativo, valorizando a relação aluno-conhecimento. Incita ao espírito crítico e ao exercício epistemológico da própria prática profissional.

\footnotetext{
${ }^{3}$ Reuven Feuerstein, nascido na Romênia no ano de 1921. Nos meados da década de cinqüenta deu origem a sua teoria da Experiência de Aprendizagem Mediada (EAM), que dá suporte ao mediador, interpondo-se e intervindo entre aquele que é mediado e os estímulos apresentados, adaptando-os às suas próprias necessidades.
} 
Portanto, seu caráter não é punitivo, técnico ou de expressão quantitativa, mas insere-se a favor da qualidade do que é ensinado e aprendido pelo aluno como parte de um processo de formação contextualizada e contínua no que diz respeito àformaç ão profissional.

A avaliação releva a emissão de valores e a análise do processo de elucidação do docente e de seu aprendiz para a identificação de questões a serem resolvidas e aperfeiçoamentos necessários. Fomenta-se a partir de discussões que identifiquem quem é o avaliador, o que pretende avaliar, para que avaliar, em que circunstância e como ocorrerá. Em vista disso é a avaliação um instrumento de múltiplas utilidades.

A avaliação pode contribuir de forma relevante para que a aprendizagem ganhe significado. Mas para isso, há de se repensar a marca do ensino nas universidades, onde o enfoque percebido é a valorização do conjunto de informações transmitidos aos alunos a fim de garantir densidade teórica aos mesmos. E, como desculpa para tal equívoco, recorrem às frases de rodapé que acusam a competitividade existente no mercado de trabalho como a grande responsável pela necessidade de tamanho volume de informações.

Contudo, será que o volume de informações transmitido aos alunos garante o aprofundamento necessário para a formação do profissional competente? Ou será que a avaliação em prol da verificação se toda a informação transmitida fora de fato apreendida pelo aluno responde æ̀s exigências da atual demanda do mercado de trabalho? Em que momento a preparação do futuro profissional ocorre se não há tempo para momentos de reflexão e discussão que vêm enriquecer o processo cognitivo? Na corrida contra o tempo, o aluno precisa se calar para o professor falar, dar as respostas certas que não requerem perguntas antecedentes ou incertezas, pois o conhecimento já está pronto e acabado. Como conseqüência, o processo educativo se depara com a desmotivação pelo aprender e a paúra de ser avaliado, ao mesmo tempo em que a nota e a freqüência æ̀s aulas se sobrepõem ao ap render a aprender numa contínua construção do saber.

Por certo que muitos professores resistem a mudanças, principalmente quando o assunto é avaliação. Eles se mostram convictos de que a concepção que têm sobre a qualidade de ensino é a melhor, a única, a perfeita e avançados em suas teorias pedagógicas.

Contudo, o mundo tem sofrido mudanças e, conseqüentemente, as universidades também fazem parte dessas mudanças. Caso se omitam a busca de respostas para as exigências da atualidade, se encontrarão engessadas frente aos desafios que vêm surgindo para a formação do futuro profissional.

A avaliação no ensino superior precisa ser repensada e examinada com cautela a fim de que não dê continuidade à tradição de dogmatizar conteúdos, de enfocar a memorização, de im por o óbvio, de atemorizar e punir. Ela precisa sair da reta da extrema objetividade para um trabalho processual, onde alunos e professores exploram as informações de forma a resgatar o interesse pelo processo de aprender.

Para tanto, é necessário que haja um "contrato didático" entre alunos e professores visando à construção de condições favoráveis para que o processo de ensino e aprendizagem abrigue propostas e alternativas de avaliação compromissadas com o desenvolvimento pleno dos alunos. Isto é, que a avaliação não se realize de forma alienada, mas interconectada com o comprometimento de preparar o aluno tendo em vista as multifaces de sua formação que valorizam a dimensão histórica, social, política, ética, filosófica e cognitiva. 
Tal avaliação vista como um processo contínuo na formação do aluno deve valorizar o desenvolvimento da autonomia intelectual e da criticidade epistemológica. Logo, faz-se necessário que o professor faça uso da intencionalidade a fim de que defina quais serão os instrumentos adequados a serem utilizados no processo de avaliação.

Tomando como ponto de partida a avaliação como um processo contínuo, clarifica-se a idéia de que a mesma não é constituída apenas por provas orais ou escritas. Pelo contrário, ela abarca um conjunto de instrumentos que substanciam sua articulação no processo ensino-aprendizagem. Daí a necessidade do professor, enquanto ser humano provido de criatividade, esquadrinhar diferentes formas de avaliar, levandose em conta as questões: quem é o meu aluno? Como ele aprende? Em que contexto histórico-social está inserido? O que será avaliado? Por que avaliar? E, finalmente, como avaliar?

\section{INTERDISCIPLINARIDADE}

A questão da interdisciplinaridade permeia a relação de trocas de experiências e o diálogo entre professores e suas disciplinas. Visa gerar uma relação de reciprocidade, mutualidade e interação que possibilita o diálogo entre os envolvidos para agirem coletivamente em busca de transformações diante de um dado problema ou situação.

Por meio dela abrem-se caminhos para a instauração do processo de transdisciplinaridade que pressupõe essencialmente o movimento transcultural gerado pela postura de reconhecimento que a complexidade humana e suas relações com o saber não podem se dar de forma fragmentada, mas sim por meio da incorporação de novos fatos àrealidade contextual, resultante do próprio conhecimento construído. É uma forma de fazer ciência.

Todavia para que a interdisciplinaridade se realize é preciso atentar para a necessidade da promoção consciente de diálogos, de conversas entre o professor e seus colegas professores, entre os professores e seus alunos, salientando que a diversidade das áreas do conhecimento contribui significativamente para uma formação profissional de qualidade.

A concepção de uma educação que não se afasta da formação integrada do cidadão contribui para a construção de uma ciência compromissada com a questão da ética e do conhecimento científico não alienados à realidade contextual do aluno no processo ensino-aprendizagem. Logo, numa visão interdisciplinar, o que deve prevalecer é o coletivo em prol da construção do indivíduo que irá interferir em transformações processuais na sociedade a qual pertence.

\section{CONCLUINDO}

Resta-nos dizer que os aspectos aqui comentados são pilares importantes na construção do conhecimento que é uma responsabilidade da universidade enquanto Instituição formadora de profissionais. Contudo, precisam ser estudados, aprofundados, refletidos, analisados e discutidos pelo professor. Somente o conhecimento apreendido e interiorizado se torna de fato útil, pois ao contrário, pode-se passar apenas por informações recebidas, acumuladas e arquivadas em nossa mente.

Há muito que se tratar em educação. Uma imensidão de assuntos pertinentes à didática e que precisam ser investigados no espaço universitário. Entretanto, nos limitamos a dialogar com a questão do 
exercício do espírito crítico, da criatividade, da intencionalidade, da avaliação e da interdisciplinaridade como pontos indispensáveis a serem abordados pelo professor em sua aula.

À medida que passamos a explorar o universo do ser humano e sua formação, descobrimos que é inesgotável a capacidade de saber, de saber fazer, de saber ser e de saber conviver do homem. Cabe a universidade descobrir novas formas de exercer seu potencial criativo no processo de construção do conhecimento de seus alunos, não temendo apaixonar-se pelo ensino e pelas inquirições que venham surgir, pois estas, são as pegadas que nos levarão a pensar mudanças necessárias no universo da educação do homem.

\section{REFERÊNCIAS}

Castanho, M.E.L.M.; Veiga, I.P.A. (Orgs.). Pedagogia universitária: a aula em foco. Campinas: Papirus, 2000.

CastanHo, S.; Castanho, M.E.L.M. Temas e textos em metodologia do ensino superior. Campinas: Papirus, 2001.

CASTANHO, S.E.M. A universidade entre o sim, o não e o talvez. In: VEIGA, I.P.A.; CASTANHO, M.E.L.M. (Orgs.). Pedagogia universitária: a aula em foco. Campinas: Papirus, 2000.

COMTE-SPONVILLE, André. Pequeno tratado das grandes virtudes. São Paulo: Martins Fontes, 1995.

MORAIS, J.F.R. A criticidade como fundamento humano. In: VEIGA, I.P.A.; CASTANHO, M.E.L.M. (Orgs.). Pedagogia universitária: a aula em foco. Campinas: Papirus, 2000.

SAUL, A. M. Avaliação emancipatória: desafios à teoria e à prática de avaliação e reformulação de currículo. 5 ed. São Paulo: Cortez, 2000.

SEVERINO, A. J. Educação, ideologia e contra-ideologia. São Paulo: EPU, 1986.

UNESCO. Declaración mundial sobre la educación superior en el siglo XXI: Visión y acción. Paris: UNESCO, 1998a. 


\title{
Contactar
}

Revista lberoamericana de Educación

\author{
Principal OEI
}

